\section{THE RCPE RESPONSE TO MID STAFFORDSHIRE}

The President and Vice Presidents of the College are to be commended for the rapidity, insight and balance of their response to the Mid Staffordshire Inquiry.

It would have been easy to assume that all was well north of the Border. However Mr Francis made 290 recommendations implying that major changes are required in the way that all NHS Hospitals are run. In Ten Questions About Human Error Sidney Dekker makes the point that the greatest danger to complex organisations is what members of staff accept as ordinary.'

We have many new effective treatments available to us, but have come to accept as ordinary what are actually shoddy, unsafe and time-consuming processes ${ }^{2,3}$ coupled with inadequate measures of quality and safety. For example the four-hours target in the Accident and Emergency (A and E) Department became Sam Shem's 'GOMER - Get Out of My Emergency Room' patients, rather than 'Attend to the patient swiftly, make a good diagnosis, start treatment and direct the patient to the correct care team within four hours'. Excellent nurses became patient movers working against the clock and the penalties for breaching the target.

\section{Infrastructure}

We also accept inadequate infrastructure as ordinary and satisfactory. In our Trust we close beds every year in the winter because of norovirus outbreaks. It is obvious to me that if every patient had a toilet and shower for exclusive personal use, and there was a sink at every bedside, the rate of ward closure would fall. We expect 'en suite' in hotels, but somehow because the NHS is 'free at the point of care', we are willing to accept lower standards. We need to have new thinking on hospital architecture.

\section{Ward rounds}

I believe that the daily bedside clinical review on ward rounds is one of the fundamental and vital processes for safe, swift, effective care of inpatients. Failings in ward round processes must be addressed in response to the Francis Inquiry. During the last four years my team has been trying to improve the quality, safety, effectiveness and efficiency of the clinical care that we deliver on post take and routine wards rounds. ${ }^{5}$ This has provided me with some insights into how far we have slipped from 'the standards of care which we would expect for ourselves and our families.' We have also developed some processes to improve quality and safety on ward rounds, particularly around teamworking (a copy of some of the forms we have implemented can be found online in the Journal section of the College website).

Our recent work on ward rounds is entirely consistent with this being the best model of care, with the doctors, nurses and allied professionals working in one team, in one geographical area, with the minimum of boarding and 'safari ward rounds'. Forthcoming data from NHS Scotland will underline the dangers of being a 'boarder', with an increase in mortality for those forced to board. Hospitals must strive to maintain enough spare bed capacity to ensure that the right patient is delivered to the right expert care team on the right ward, first time. We would not expect a patient with complex liver disease to have a consultation in a diabetes clinic, because there was a vacant slot, yet the same patient may well end up on a Diabetes Ward only because there was a vacant bed, with another patient waiting in $A$ and $E$.

The break up of the Firm structure does undermine teamworking, and has not yet been compensated for by the training of Foundation Doctors with true generic skills in acute care. We have not emphasised enough the need for training in professional communications in such basic matters as notes writing, written and verbal handovers, verbal case presentations on rounds, or even formalising the whole bedside review as has been done with structured interdisciplinary bedside rounds (SIBR) in Atlanta and Australia. ${ }^{6}$

\section{Nurses}

Communication between doctors and nurses seems to have deteriorated seriously since I was a Junior Registrar in Edinburgh in the 1980s. Atul Gawande encourages doctors to 'stop moaning, do something and count'. In April 2009, we developed a checklist to improve both the reliability of our clinical care on ward rounds, and our communications with nurses. ${ }^{5}$ The data stimulated our Trust to invest in more nurses in the Acute Medical Unit and improved our rate of 'nurse at the bedside' and 'report back'. However on my Consultant-led routine rounds on the general wards the rate for 'nurse at the bedside' remains below $50 \%$. I am sure the rate is even lower when the junior doctors do interim review rounds. The joint Royal College of Physicians of London and Royal College of Nursing recommendations and the Francis report both state that 'nurse at the beside' is essential for safe, effective daily care. ${ }^{8}$ However ordinary or average the nurse to patient ratio in relation to other Trusts, in the NHS we simply do not have enough ward nurses, healthcare assistants, therapists and clerks to ensure that basic human care is given to patients, as well as a senior nurse being available for the crucial clinical communications and decision-making at the bedside. I believe that a lot of doctors' and nurses' time is wasted in non-productive activity, and this could be released at low cost.

\section{The need for modern IT equipment}

Our counting of ward rounds has also produced evidence for how long a ward round takes, when conducted to a set of standards and processes. Doing this work has revealed how difficult it is to work both swiftly and safely. Diagnosis depends on a careful medical interview, backed 
up by quick access to a list of current medications, the past notes and current results. In Scotland you have the immense advantage of the Emergency Care Summary to move you swiftly ahead on the drugs list and allergies. Our night-take teams in England are frequently working in the dark! Our IT software seems designed to make it hard to see results, and older correspondence, with multiple systems, requiring many user names and passwords. Lean principles tell us that every effort has to be made to make the production lines work smoothly and stress-free. This is not what happens, making misdiagnosis much more likely. ${ }^{9}$ Our end-of-bed folders are so full of verbose, impenetrable charts, that even checking the drug prescriptions can be such an effort that it is not done.

I believe that many of the problems identified by $\mathrm{Mr}$ Francis may be solved by going 'back to the future', while developing smart new ways of working with IT that delivers the information needed to every clinician and patient at the bedside. We need to replace the white coat, pockets stuffed with the British National Formulary and the Oxford Handbook of Clinical Medicine with mobile IT hardware and rapid access to clinical information about the patient and summary clinical recommendations and information for immediate use at the bedside.

\section{Commissioning services}

NHS England has moved to a new way of commissioning services. As ever this seems to get bogged down in detail, failing to recognise that the fundamental basic processes of care are seriously failing. In response to the Francis Inquiry I suggest that Commissioners for acute unscheduled medical care make some very simple demands:

I. Medical and geriatric patients' full admission clerking should be started within 30 minutes of the patient being available to the medical admitting team, and completed within 90 minutes. This would be excellent generic training for Foundation Doctors, but would require radical reallocation of Foundation Doctors to $A$ and $E$ and Acute Assessment areas.

2. Senior review of the full clerking by a Consultant or Specialist Registrar (SPR) should take place within four hours.

3. Thereafter every acute inpatient should experience a daily (seven days a week, 52 weeks a year) bedside clinical review by a team consisting of a minimum of a doctor and a nurse. This review should take place before noon. This would require radical reworking of Consultants' contracts, working patterns and clinic scheduling.

4. By 09:00 all inpatients should have had breakfast, been to the toilet, washed, had regular medications given and observations taken, ready for the rounds. Every decision made on rounds, major or minor, has the potential to affect the whole of the remainder of the patient's life. The right information and right environment is needed for making these high-risk decisions and for active safety checking.

5. At the moment of discharge from hospital a useful, legible, comprehensive yet brief summary should be sent by email to both the general practitioner and the patient.

I believe we need a lot more radical thinking than I have outlined to be able to reverse all of the shortfalls in acute medical care. We need to ask the 'five whys' of nearly every process, especially the ones we accept as ordinary e.g. why are patients fully clerked by an $\mathrm{A}$ and E Senior House Officer (SHO), then fully reclerked by a Medical SHO, asking many of the same questions, and using completely non-integrated notes, so adding delay to care? However, I also believe that much can be achieved at little cost by getting right back to the basics of our everyday ordinary mundane processes. It is getting the ordinary right that is important in response to the Francis Report.

Dr Gordon Caldwell FRCP London

Consultant Physician, Worthing Hospital

Email gordon.caldwell@wsht.nhs.uk

\section{References}

I Dekker S. Ten questions about human error. New Jersey: Lawrence Erlbaum Associates Inc; 2005.

2 Caldwell G. The written and unwritten rules of NHS IT. British Journal of Healthcare Management 20II; I7:284-90.

3 Caldwell G. Clinically lean; 'cutting the crap'. Acute Medicine 2012; II:I6I-5.

4 Shem S. The house of God. London: Black Swan; 1978.

5 Herring R, Desai T, Caldwell G. Quality and safety at the point of care: how long should a ward round take? Clin Med 201 I; I I:20-2. http://dx.doi.org/I0.786 I/clinmedicine.I I-I-20

6 Stein J, Mohan A, Payne $C$ et al. Mortality reduction associated with structure, process, and management redesign of a hospital medicine unit [abstract]. Journal of Hospital Medicine 2012; 7 Suppl 2 :II5. Available from: http://www.shmabstracts.com/abstract.asp?Meeting ID=783\&id=97658

7 Gawande A. Better: a surgeon's notebook on performance. London: Profile Books; 2008.

8 Royal College of Physicians and Royal College of Nursing. Ward rounds in medicine: principles for best practice [Internet]. London: RCP; 2012 [cited 2013 May I]. Available from: http://www.rcplondon.ac.uk/ sites/default/files/documents/ward-rounds-in-medicine-web.pdf

9 Caldwell G.What is the main cause of avoidable harm to patients? BMJ 2010; 34I:c4593. http://dx.doi.org/l0.1 I36/bmj.c4593 